\title{
Palmtop EPMA
}

\author{
Jun Kawai, Yasukazu Nakaye and Susumu Imashuku \\ Department of Materials Science and Engineering, \\ Kyoto University, Sakyo-ku, Kyoto, \\ Japan
}

\section{Introduction}

We have been developping palmtop electron probe X-ray microanalyzers (EPMA) for these several years [1-4] and succeeded to make such an instrument recently [3], and in the present chapter, we describe how to make an instrument in detail. The EPMA is an instrument to perform microanalysis (micrometer area elemental analysis) of any kinds of samples, such as metals, alloys, minerals, environmental and biological samples, by using an electron beam. Usually 10-30 keV kinetic energy electron beam is focused less than $1 \mu \mathrm{m}$ in order to irradiate a sample, and consequently to excite characteristic X-rays such as $K \alpha(2 p$ $\rightarrow 1 \mathrm{~s})$ or $\mathrm{L} \alpha(3 \mathrm{~d} \rightarrow 2 \mathrm{p}$ ) lines. From the energy and intensity of the characteristic X-ray lines, the kind (qualitative analysis) and concentration (quantitative analysis) of the elements in the specimen can be analyzed. Commercially available EPMA instruments are usually large (need a room of at least $3 \mathrm{~m} \times 5 \mathrm{~m}$ to install) and expensive instruments (a few $10^{5} \mathrm{USD}$ ). The palmtop EPMA we describe in the present chapter has features as follows and different from the conventional EPMA.

1. Small size. The size of the main part (sample holder, X-ray emission part, and the electron gun) is palmtop size. Typically less than $3 \mathrm{~cm}$ diameter and $5 \mathrm{~cm}$ length (Fig.1), but can be smaller than this size. The limitation of the size is due to the high voltage discharge distance.

2. Electric battery driven. The electron gun is driven by two $1.5 \mathrm{~V}$ electric D-batteries (Fig. $2)$, i.e. $3 \mathrm{~V}$ is enough for high energy $(>10 \mathrm{keV})$ electron beam in order to excite characteristic X-rays.

3. The X-ray detector is Amptek Si-PIN detector (Fig. 3). Thus the size of the detector is also small. We use analog type X-ray detector amplifier. The size of the detector preamplifier is typically around $7 \mathrm{~cm} \times 4 \mathrm{~cm} \times 3 \mathrm{~cm}$. The temperature control of the detector unit and bias power supply from the Amptek Co. is needed (Fig.3). Thus we need power supply for the Si-PIN controller to cool down the detector and bias voltage. However usually low voltage (5-12 V) DC is enough.

4. The pulse height analyzer (PHA) commercially available is not used, but we use a musician's amplifier and Windows computer as an alternative to the commercially available PHA [5-8]. This part is usually called DSP (digital signal processor). Usually a DSP is an expensive device which costs between 5000 and 10000 USD. However the musician's amplifier (Fig. 4) is typically less than 500 USD. 
5. Vacuum in the sample chamber is of the order of $10^{-2}$ Torr (or $\sim 1 \mathrm{~Pa}$ ). This vacuum level is equivalent to the vacuum reached by a small rotary pump. Higher the vacuum than $10^{-2}$ Torr, in other words, too good or too high vacuum is not effective for high intensity $\mathrm{X}$-ray emission. Too high vacuum down to $10^{-6}$ Torr needs expensive turbo molecular pump or oil diffusion pump, however, the residual gas is an electron source for the electron gun, thus such a high vacuum reduces the intensity of X-rays emitted. Too low vacuum up to $10^{-1}$ Torr will make electric discharge and $10^{-2}$ Torr is suitable for the present instrument. This vacuum level is suitable for oil sealed rotary pump (Fig. 5).

6. The sample exchange is easy because the vacuum seal is usually rubber O-ring (Fig. 6) and can be easily opened after air leaked.

7. The electron beam size is not micrometer, but as wide as the vacuum vessel diameter. It irradiates whole part of the sample and thus sample holder as well as vacuum vessel materials are excited. However the sample size can be as small as possible depending on the signal intensity. A typical size of the specimen is $50 \mu \mathrm{m}$ diameter $\times 5 \mathrm{~mm}$ length metal wire. Thus single sand particle can be measured.

8. The palmtop EPMA can be made in laboratory, even by students without special experience.

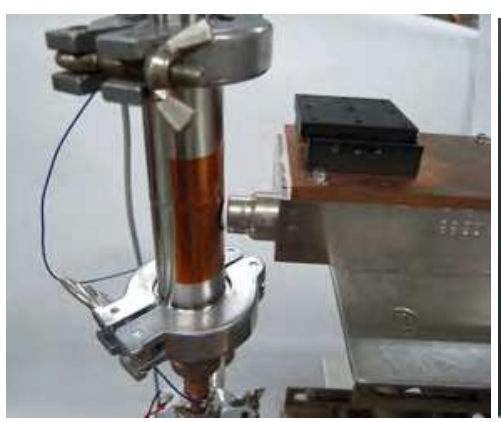

a

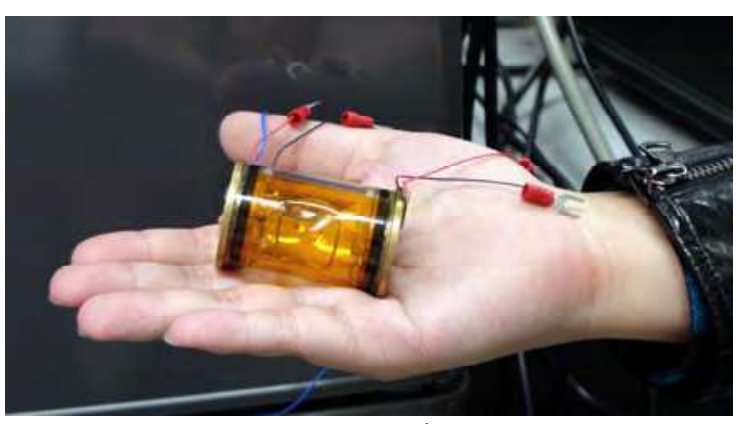

$\mathrm{b}$

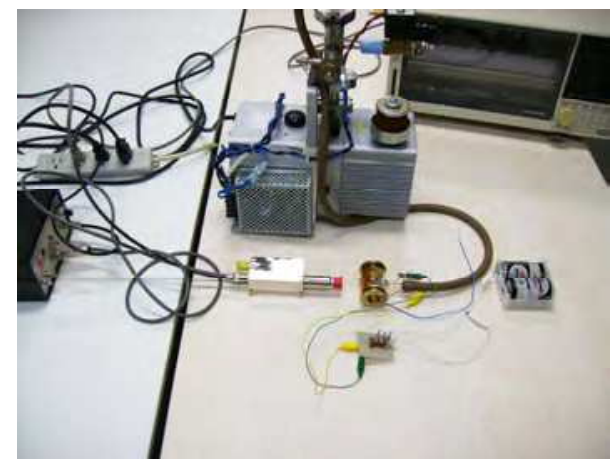

C

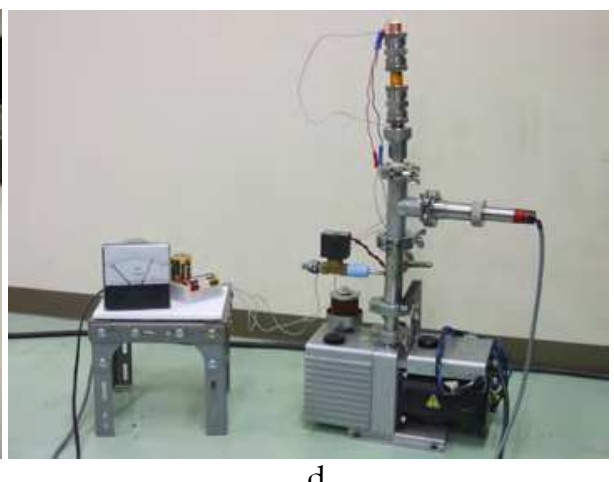

d

Fig. 1. Various kinds of palmtop EPMA made in our laboratory. (a) NW25 nipple is used for vacuum chamber, a hole is sealed by Kapton tape. (b) Glass type vessel is on the palm. (c) The whole system of the palmtop EPMA. (d) Another type of palmtop EPMA, with Pirani vacuum gauge. 


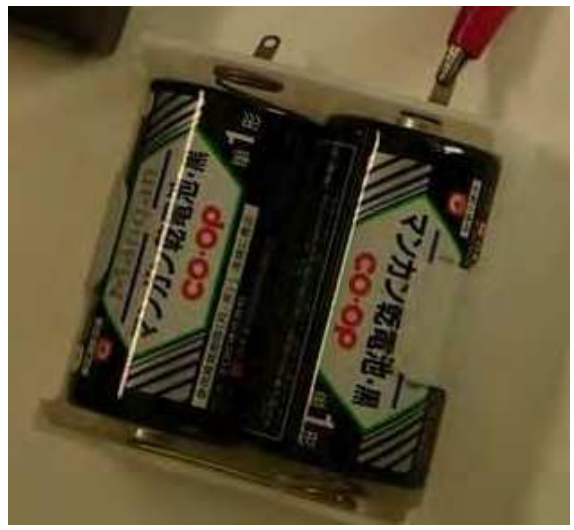

Fig. 2. Electric D-batteries.

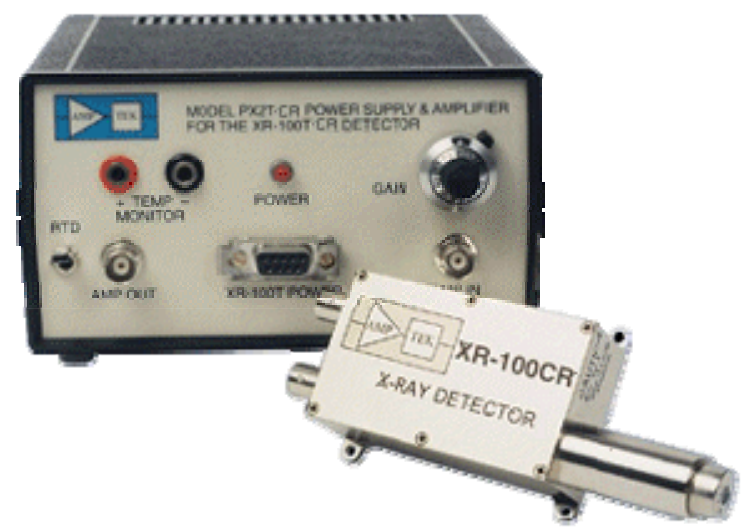

Fig. 3. Amptek Si-PIN X-ray detector (taken from Amptek Web page)

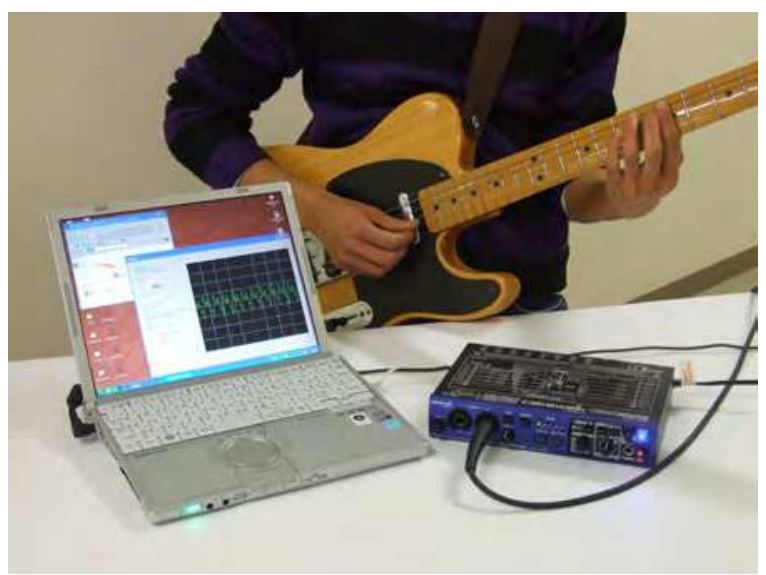

Fig. 4. Musician's amplifier for DSP. 


\section{The parts prepared before to build a palm-top EPMA}

The following mechanical or electronic parts should be prepared to build up the instrument.

1. Rotary pump. Oil sealed rotary pump to reach to the vacuum level of the order of $10^{-2}$ Torr or around $1 \mathrm{~Pa}$ is needed. The smaller size rotary pump is preferable. Single phase $100 \mathrm{~V}$ power supply is enough. A typical rotary pump used in the present work is shown in Fig. 5.

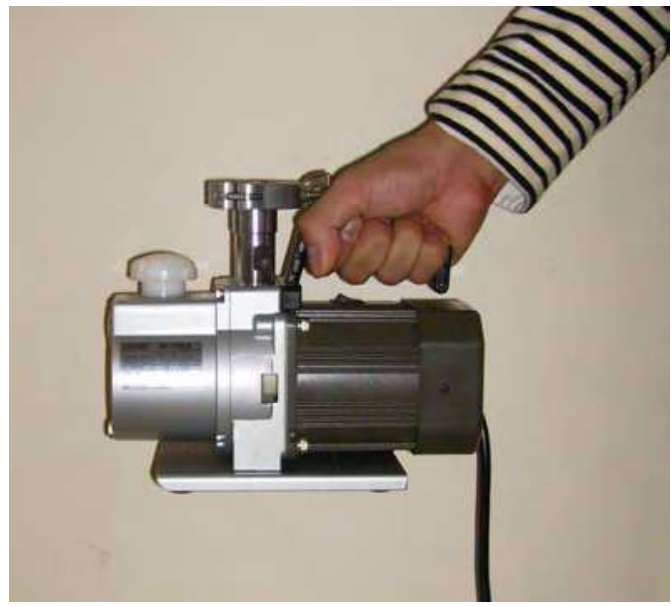

Fig. 5. A small rotary vacuum pump.

2. Si-PIN X-ray detector. Amptek X-ray detector (Fig. 3) is needed. It costs usually less than 4000 USD including the preamplifier. The controller of Peltier device inside the SiPIN detector to cool the Si-PIN device is needed. Usually the power supply associated with the Si-PIN detector is preferable. If Si-PIN X-ray detector is not available, GeigerMüller counter is alternatively used for check the X-ray emission. The Geiger-Müller counter is available less than 500 USD (Fig. 7).

3. Notebook size computer. Windows computer to control the Amptek Si-PIN detector, to display the X-ray spectra, and to control and analyze the digital X-ray signal is needed as is shown in Fig. 4. Several USB devices are connectable at the same time.

4. $\mathrm{LiTaO}_{3}$ single crystal (one piece). The size is around $3 \mathrm{~mm}(x) \times 3 \mathrm{~mm}(y) \times 5 \mathrm{~mm}(z)$ (Fig. 8). The $z$ direction should be known. From Shin-Etsu Chemical Co. Ltd., Japan, this single crystal is available by less than 200 USD. Several other companies treat $\mathrm{LiTaO}_{3}$ single crystal of the size of $10 \mathrm{~mm}$ length and $3 \mathrm{~mm}$ diameter with similar price. Other alternative is $\mathrm{LiNbO}_{3}$. These materials are called pyroelectric crystals. If these single crystals are not available, at the first stage, you can use PZT stone used in the cigarette lighter to ignite.

5. Peltier device. The size of Peltier device in Fig. 9 is $8 \mathrm{~mm} \times 8 \mathrm{~mm}$. To drive this Peltier device, $3 \mathrm{~V}$ electric D-batteries are needed. (Fig. 2)

6. Glass vessel or steel nipple. Single crystal, peltier device, and sample should be inside of the vessel or nipple to evacuate by the vacuum pump (Fig. 1).

7. If possible, Pirani vacuum gauge is helpful to build up the instrument. 
Fig. 6. O-ring, with brass specimen holder. Graphite is better than brass.

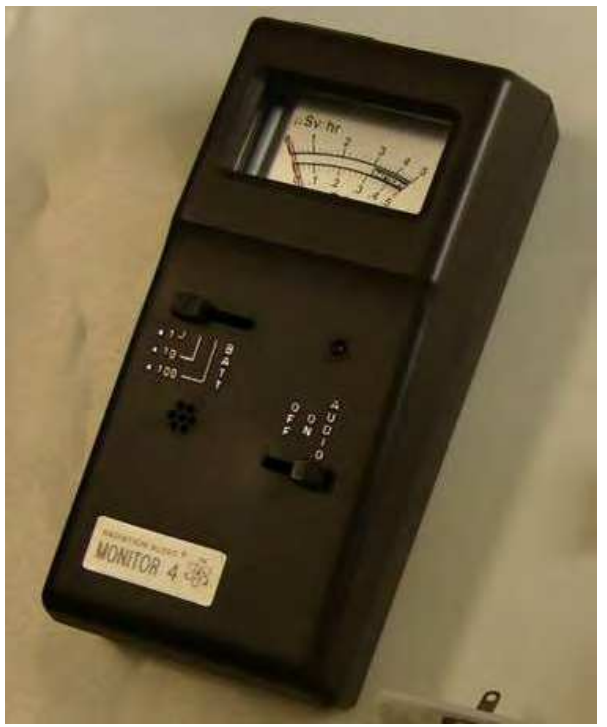

Fig. 7. Geiger-Müller counter

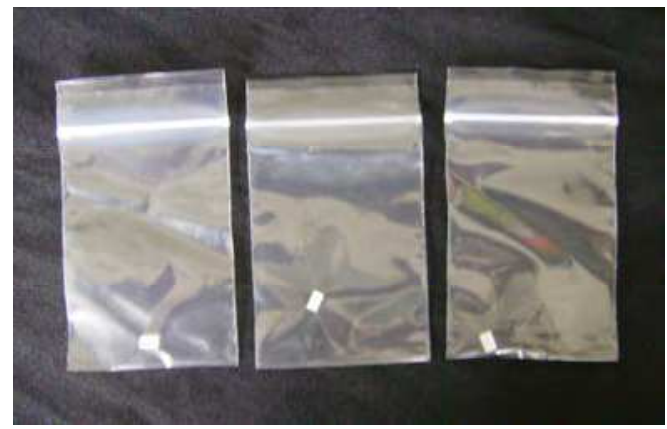

Fig. 8. $\mathrm{LiTaO}_{3}$ single crystals in plastic bags. 


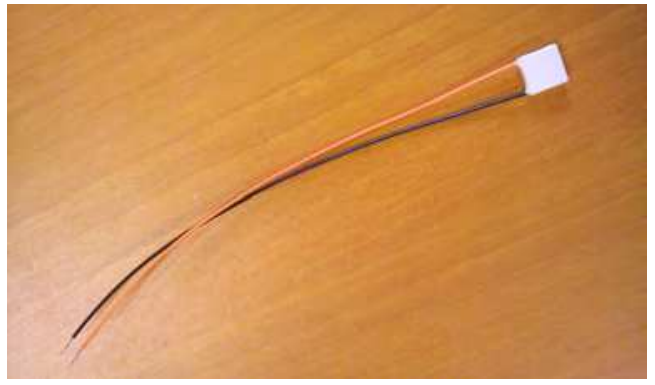

Fig. 9. Peltier device of size $8 \mathrm{~mm} \times 8 \mathrm{~mm}$.

\section{Principle}

The pyroelectric crystal is a material usually called as ferroelectric material. A mineral named tourmaline has similar characteristics. This is because the center of gravity of the plus charge and minus charge ions are not the same place in the crystal, but has a distance along $z$ direction. Thus the extension or compression of these materials will produce electric high voltage. If a single crystal of the thickness of $1 \mathrm{~mm}$ in $z$ direction of $\mathrm{LiTaO}_{3}$ changes the temperature (usually the heating will expand, and cooling will compression) from room temperature $\left(25^{\circ} \mathrm{C}\right)$ to say 50 or $100{ }^{\circ} \mathrm{C}$, then $10 \mathrm{kV}$ high voltage will be produced. Thus when the crystal with thickness of $5 \mathrm{~mm}$ will produce $50 \mathrm{kV}$ and $10 \mathrm{~mm}$ will produce 100 $\mathrm{kV}$. When this single crystal is put into low vacuum such as 10-2 Torr, the electrons in the residual gas will be accelerated by this high voltage to hit the surface of the pyroelectric crystal or counter electrode of the pyroelectric crystal [9-19], as shown in Fig. 12 below. If a specimen is attached on the counter electrode, the electrons accelerated by the high voltage between the pyroelectric (-HV) and counter electrode $(0 \mathrm{~V}$, grounded to earth) will hit the specimen. Consequently the X-rays are excited by the ionization of electrons by the bombardment of the accelerated electrons. Then the ionized electrons will contribute next instance to be accelerated to hit the specimen again and again, until the surface charge is neutralized. The vacuum should be not too good. Usually better side of $10^{-2}$ Torr is the suitable vacuum for this experiment. The heating and cooling of the pyroelectric crystal should be performed by a Peltier device. The temperature control of $50{ }^{\circ} \mathrm{C}$ from the room temperature $\left(25^{\circ} \mathrm{C}\right)$ is possible. The polarity of the surface changes when heated and cooled. Thus the electrons are moved inversely when heated and cooled. Usually it is heated for a few minutes, then next few minutes the pyroelectric crystal should be cooled. When the electron hits the pyroelectric surface, the X-rays are not from the specimen but Ta X-rays are observable from $\mathrm{LiTaO}_{3}$.

\section{How to build the main part of the palmtop EPMA}

The Peltier device and the pyroelectric crystal are on the copper rod as shown in Fig. 10. They are glued by silver paste. The reason using the copper rod is its good heat conductivity as well as the electric conductivity. The one side of pyroelectric crystal glued to the Peltier device should be grounded to the earth. The heat created by the Peltier device should be diffused through the copper rod. Thus both silver paste and copper rod are suitable for this purpose. 


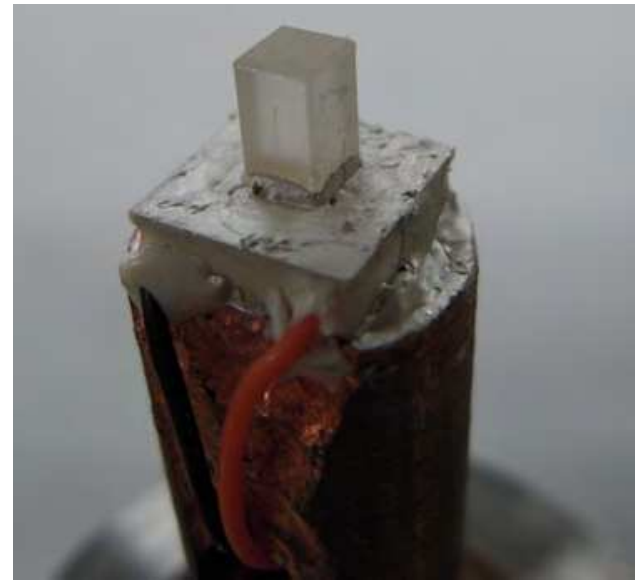

Fig. 10. Pyroelectric crystal, Peltier device, and copper rod, glued by silver paste.

The anode is graphite rod as shown in Fig. 11. The specimen will be put on the graphite rod by double sided carbon adhesive tape. This is also because of the electric conductivity. The graphite rod and copper rod should be electrically connected to make the same ground potential. The X-ray intensity becomes weak if the electric connection between the copper and graphite rods is removed. Here the graphite is used as the specimen holder. The reason we use graphite and carbon adhesive tape is because the specimen and holder are hit by the electron beam from the pyroelectric crystal, and the carbon $\mathrm{K} \alpha \mathrm{X}$-rays from graphite as well as carbon adhesive tape are negligible because the $\mathrm{C} \mathrm{K} \alpha$ energy is about $300 \mathrm{eV}$ and thus such a low energy soft X-rays are strongly absorbed by the air and window of the vessel (Kapton), resulting the X-rays from graphite rod and carbon adhesive tape are not detectable.

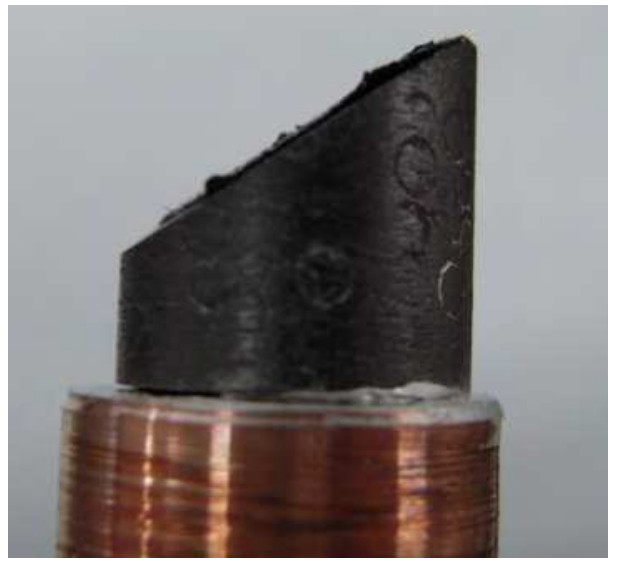

Fig. 11. Graphite anode as specimen holder.

The lead wire from the Peltier device is inside of the vacuum vessel, and should go through the vacuum boundary to the outside of the vessel without the leak of the vacuum by using 
epoxy glue. If possible addition of thermocouple is helpful to measure the temperature of the Pettier device.

Both of the electrodes are sealed inside the glass or stainless pipe by rubber O-ring. Viton rubber O-ring is preferable. If NW-25 type quick coupling flange is directly used, this is quite easy to seal the vacuum. The stainless steel nipple of NW-25 or glass pipe should have ca $5 \mathrm{~mm}$ diameter through-hole to go through the X-rays, and this through-hole should be sealed by thin Kapton film. Adhesive type Kapton tape is commercially available. Polyester, PET (polyethylene terephthalate), or Mylar films glued by epoxy resin adhesives are alternative to the Kapton tape. The structure of the palmtop part is illustrated in Fig. 12.

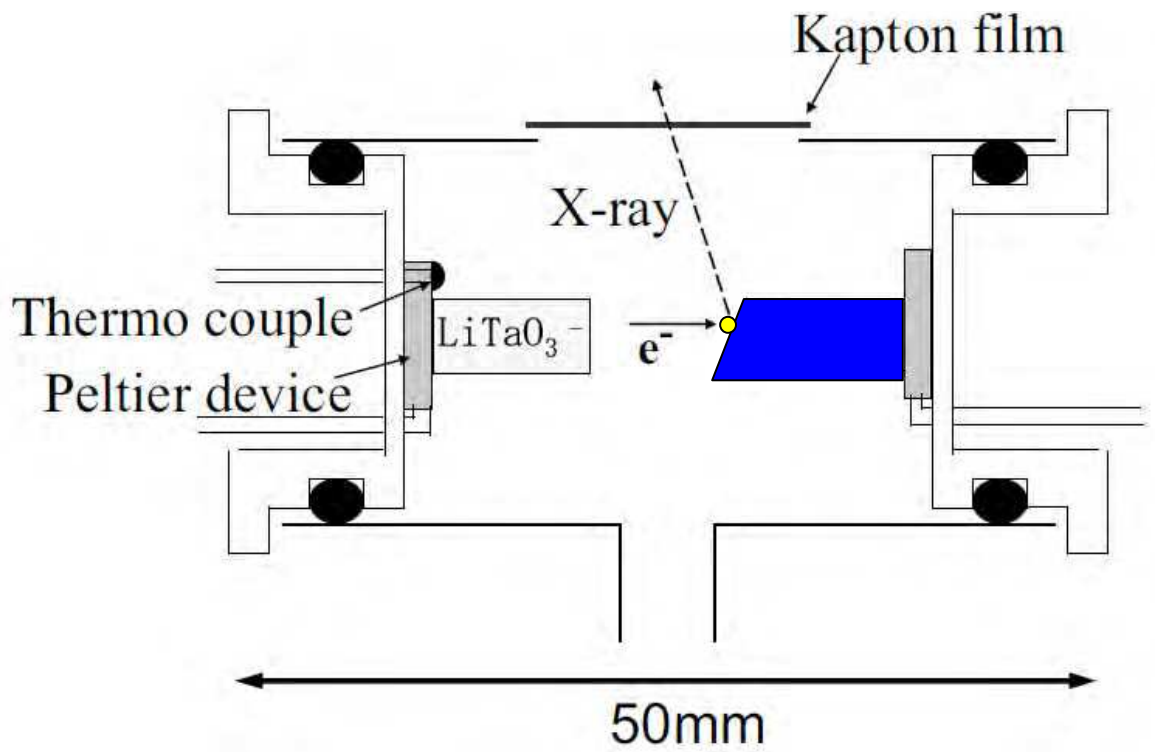

Fig. 12. Illustration of the palmtop EPMA.

\section{How to operate}

Putting stainless steel small plate, the size of which is typically $5 \mathrm{~mm} \times 5 \mathrm{~mm}$, on the graphite rod, by double sided carbon adhesive tape, then the vacuum vessel should be evacuated by the rotary pump. The connection between the vessel and the pump should be thick rubber tube. At the first experiment, the stainless steel as the specimen should be as large as possible to get enough X-ray intensity. The stainless steel is usually composed of 18 $\% \mathrm{Cr}, 8 \% \mathrm{Ni}$, and the rest $\mathrm{Fe}$. Thus we can observe $\mathrm{Cr}$, $\mathrm{Fe}$, and $\mathrm{Ni} \mathrm{K} \alpha$ and $\mathrm{K} \beta$ lines. After one or two minutes evacuation by the rotary pump, the vacuum reached to better than $2 \times 10^{-2}$ Torr. Then the Peltier lead wires should be connected to 3 V D-batteries. Waiting for 10-20 seconds, the Geiger-Müller counter reacts the X-rays, and the intensity is not very strong but we can hear the X-ray counts sounds from the Geiger-Müller counter as almost continuous sounds from the counter. It is more than a few tens of cps (counts per seconds). The polarity of D-battery is no problem. If the polarity is for the pyroelectric crystal being $+\mathrm{HV}$, the end of crystal is hit by the electron and X-rays of Ta are emitted. 
If you confirm the emission of X-rays from the vessel, the next step is to measure the spectra by the Si-PIN detector. It is better to become accustomed to use the Si-PIN detector to measure the X-ray spectra by using other method, such as weak radio isotopes. Then the SiPIN detector should be close to the Kapton window of the palmtop EPMA to measure the spectra. Usually the time interval to change the polarity of the D-battery from heat to cool the crystal is 1 or 2 minutes. A typical temperature change and X-ray intensity decay are shown in Fig. 13.

The spectra measured by the Si-PIN detector is shown in Fig. 14, where the peak intensity is several thousands of counts for a few minutes one cycle. The X-ray intensity is not very strong, but it is better to protect the exposure to the X-rays. Usually lead containing acrylic plate is good for protecting from the X-rays, but steel plate of the thickness of 1 or $2 \mathrm{~mm}$ is enough. The Geiger-Müller counter is not saturated during this experiment, but if the X-ray intensity is too strong when Geiger-Müller counter is directly irradiated by an 1 watt X-ray tube, then the Geiger-Müller counter will be saturated, and we cannot see the difference between no X-rays. Thus the present experiment should be performed with an expert of Xray experiments.

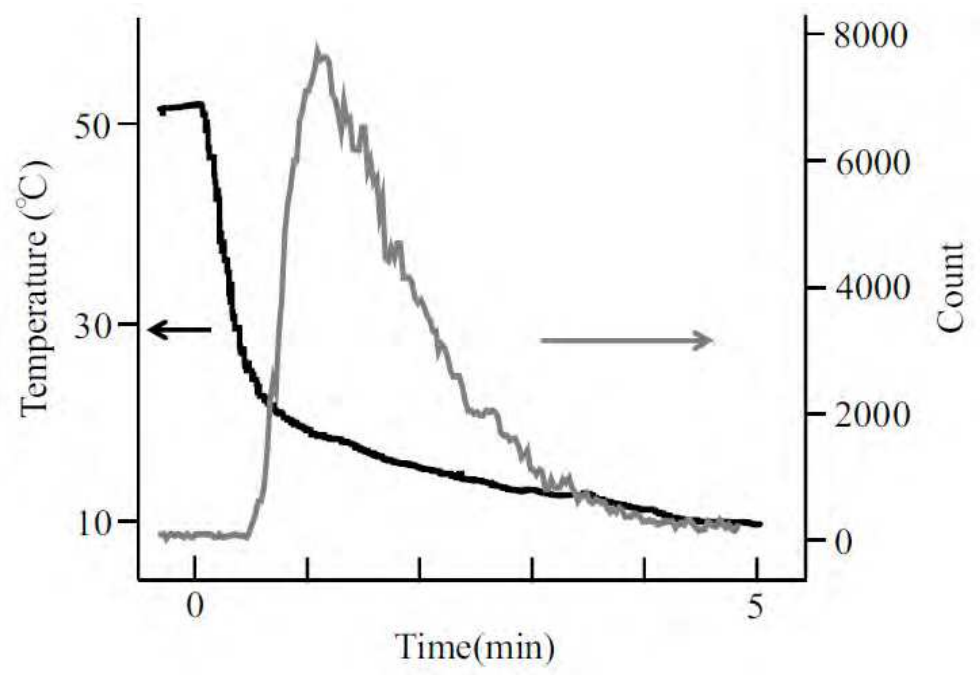

Fig. 13. Time dependent temperature and X-ray intensity after the crystal became to be cooled.

\section{Digital signal processor}

The X-ray signal from the Si-PIN X-ray detector is voltage signal. If the energy of X-rays is high, the voltage increase step-like according to the energy of the $X$-rays. Thus when the Xray energy is high, the step height is larger. If the X-ray intensity is strong, then the step frequency in unit time increases. The step height increases again and again, and finally the voltage is larger than the voltage of the power source, then the step signal is reset and starts again. Thus if the time dependent voltage increase is recorded as voice signal in the memory of a computer as the voice recorder, we can plot the X-ray spectra by differentiating the step- 
like voltage signal and plotting the frequency of the pulses against the height of the peak. This is the X-tray spectra. One of the X-ray spectra obtained in such a way is shown in Fig. 14. The X-ray intensity of our palmtop EPMA is not very strong (less than 10000 counts per minute), thus the response of analog/digital (A/D) converter for music purpose is enough (Fig. 15). The important points to use the music A/D convertor, or musician's amplifier are as follows.

1. The input of music amplifier is usually biased by a DC voltage to drive a microphone, and thus direct DC connection between X-ray pre-amplifier and music A/D converter will cause to destroy the pre-amplifier, and thus AC coupling should be used.

2. Impedance should be matched.

3. Any kind of notebook computer has microphone input, and can be used for the similar purpose, but the notebook computer inside is full of digital noises. Consequently too high level of digital noises makes it impossible to measure the X-ray spectra. This is the reason we use separate musician's amplifier.

The above function is identical to the digital oscilloscope and if you have a digital oscilloscope, you can connect your oscilloscope to the computer by a USB and import the Xray signal into your computer. After recording or during the recording, you can differentiate the X-ray signal numerically, and plot the X-ray spectra on the computer display. When you record the X-ray spectra, the peaks are not assigned at all, and the peaks should be assigned using linear relation between the voltage and X-ray energy, and the energy of the spectra of elements contained in the specimen should be assigned by an X-ray database. The resulted X-ray spectrum is shown in Fig. 14. An example of the software is provided from X-ray Precision Co. Ltd. Kyoto by the price of around 200 USD by CD-ROM, but you can make such a program by yourself.

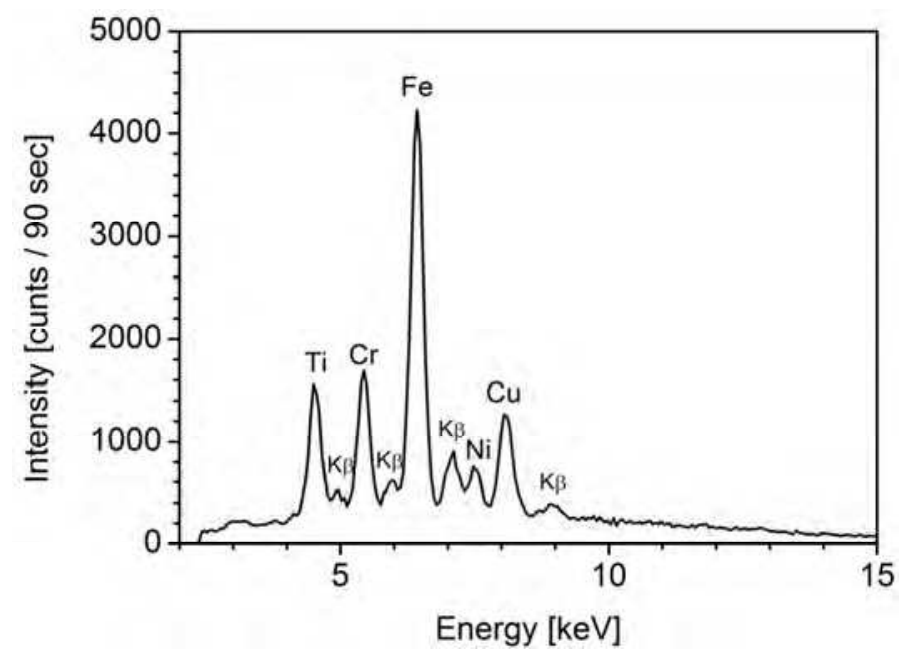

Fig. 14. X-ray spectra of steel and Ti (about 1 minute measurement). 


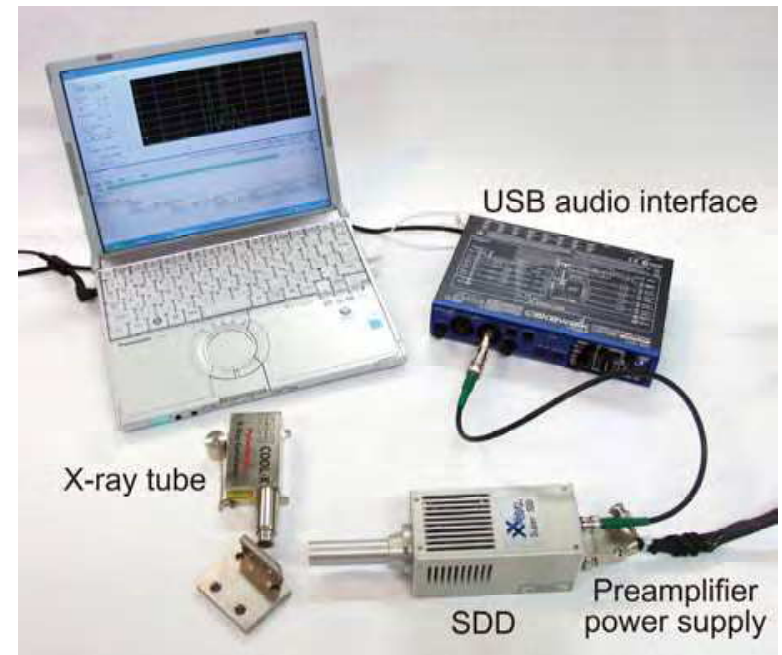

Fig. 15. Musician's amplifier connected to X-ray detector and computer.

\section{Maintenance and safety}

The surface of the pyroelectric crystal becomes dark because of the sputtered particles by the high voltage discharge will be deposited on the surface. These black fine particles are electric conductive, and thus the high voltage is not accumulated in the pyroelectric crystal. In such a case, the pyroelectric surface should be cleaned by cotton stick with ethanol to remove the dark sputtered particles. Then the X-rays will come back again.

The earth electric line is important to avoid the electric shock. Also the electric connection between the two electrodes is important to emit strong X-rays, as mentioned in the text. The $X$-ray is dangerous to be exposed even it is very weak. Thus monitoring of the X-ray intensity and shielding the $\mathrm{X}$-rays are important for experiments.

After the experiment, the rotary pump should be leaked to the atmospheric pressure. If one forgets to leak the air into the vacuum system, the oil in the rotary pump will rise up to the vacuum vessel of the palmtop EPMA to fill the vessel, and consequently the experiment is not possible any more because of the contamination by the oil. To avoid this, auto-leak valve is preferable to attach just above the rotary pump. Since the auto-leak valve, manual air leak valve, and Pirani gauge are attached to the vacuum system, the instrument shown in Fig. 1d is not a simple one but complicated by vacuum parts. All these vacuum parts are connected to the vacuum system by the NW-25 flanges.

\section{Acknowledgements}

E. Hiro and S. Terada, who contributed at the early stage of the palmtop EPMA development, are acknowledged. The authors would like to thank Asahi Glass Foundation for financial support. The computer program for music amplifier has been developed by the JST support. The first version of the palmtop EPMA was a by-product of JST Sentan project. 


\section{References}

[1] E. Hiro, T. Yamamoto, and J. Kawai: Applying pyroelectric crystal to small high energy X-ray source, Adv. X-Ray Chem. Anal., Japan, 41, 195-200 (2010).

[2] J. Kawai, Y. Nakaye, E. Hiro, and H. Ida: Application of pyroelectric crystal---a safety Xray source, Radioisotopes, 60 (6), 249-263 (2011).

[3] S. Imashuku, A. Imanishi, and J. Kawai: Development of miniaturized electron probe Xray microanalyzer, Anal. Chem. 83 (15), 6011-6017 (2011).

[4] S. Imashuku, A. Imanishi, and J. Kawai: Palmtop EPMA by electric battery, submitted to the Proceedings of the 21st ICXOM (Intern. Congress on X-ray Optics and Microanalysis, Campinas, September, 2011), AIP Conference Proceedings (submitted).

[5] Y. Nakaye, and J. Kawai: Recording X-ray spectra with an audio digitizer, X-Ray Spectrom., 39 (5), 318-320 (2010).

[6] L. Ze, Y. Nakaye, Y. Morikawa and J. Kawai: SEM-EDX with audio digitizer, Adv. X-Ray Chem. Anal. Japan, 42, 111-114 (2011).

[7] Y. Nakaye and J. Kawai: Observation of pulsed electron field emission driven by a pyroelectric crystal, Adv. X-Ray Chem. Anal. Japan, 42, 249-253 (2011).

[8] Y. Nakaye and J. Kawai: X-Ray measurement using an audio A/D converter, Adv. X-Ray Chem. Anal. Japan, 42, 255-259 (2011).

[9] J. D. Brownridge: Pyroelectric X-ray generator, Nature, 358, 287-288 (1992).

[10] J. D. Brownridge, and S. Raboy: Investigations of pyroelectric generation of $\mathrm{x}$ rays, J. Appl. Phys., 86, 640-647 (1999).

[11] S. M. Shafroth, W. Kruger, and J. D. Brownridge: Time dependence of X-ray yield for two crystal X-ray generators, Nucl. Instrum. Meth. Phys. Res., A422, 1-4 (1999).

[12] J. D. Brownridge, and S. M. Shafroth: Electron and positive ion beams and X-rays produced by heated and cooled pyroelectric crystals such as $\mathrm{LiNbO}_{3}$ and $\mathrm{LiTaO}_{3}$ in dilute gases: Phenomenology and applications, in "Trends in Laser and ElectroOptics Research", Ed. W. T. Arkin, Nova Science Pub. (2006) pp. 59-95.

[13] B. Naranjo, J. K. Gimzewski, and S. Putterman: Observation of nuclear fusion driven by a pyroelectric crystal, Nature, 434, 1115-1117 (2005).

[14] J. Geuther, Y. Danon, F. Saglime, and B. Sones: Electron acceleration for X-ray producing using paired pyroelectric crystals, Abstracts of the 6th Intern. Meeting on Nuclear Applications of Accelerator Technology (AccApp'03), San Diego, June 1-5 (2003) pp.124-128. (http://www.rpi.edu/ danony/Publications.htm).

[15] J. A. Geuther and Y. Danon: Electron and positive ion acceleration with pyroelectric crystals, J. Appl. Phys., 97, 074109 (2005).

[16] J. A. Geuther and Y. Danon: High-energy X ray production with pyroelectric crystals, J. Appl. Phys., 97, 104916 (2005).

[17] J. A. Geuther, Y. Danon, and F. Saglime: Nuclear reaction induced by a pyroelectric accelerator, Phys. Rev. Lett., 96, 054803 (2006).

[18] J. A. Geuther and Y. Danon: Application of pyroelectric particle accelerators, Nucl. Instrum. Meth. Phys. Res., B261, 110-113 (2007).

[19] J. A. Guther and Y. Danon: Enhanced neutron production from pyroelectric fusion, Appl. Phys. Lett., 90, 174103 (2007). 


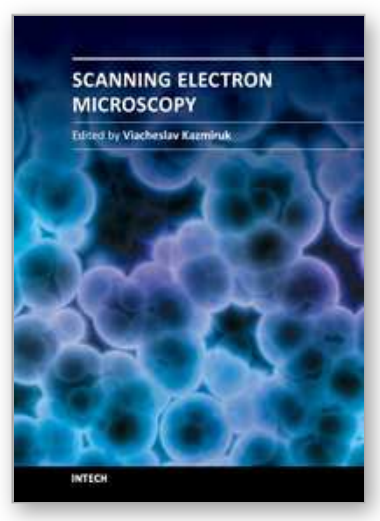

\author{
Scanning Electron Microscopy \\ Edited by Dr. Viacheslav Kazmiruk
}

ISBN 978-953-51-0092-8

Hard cover, 830 pages

Publisher InTech

Published online 09, March, 2012

Published in print edition March, 2012

Today, an individual would be hard-pressed to find any science field that does not employ methods and instruments based on the use of fine focused electron and ion beams. Well instrumented and supplemented with advanced methods and techniques, SEMs provide possibilities not only of surface imaging but quantitative measurement of object topologies, local electrophysical characteristics of semiconductor structures and performing elemental analysis. Moreover, a fine focused e-beam is widely used for the creation of micro and nanostructures. The book's approach covers both theoretical and practical issues related to scanning electron microscopy. The book has 41 chapters, divided into six sections: Instrumentation, Methodology, Biology, Medicine, Material Science, Nanostructured Materials for Electronic Industry, Thin Films, Membranes, Ceramic, Geoscience, and Mineralogy. Each chapter, written by different authors, is a complete work which presupposes that readers have some background knowledge on the subject.

\title{
How to reference
}

In order to correctly reference this scholarly work, feel free to copy and paste the following:

Jun Kawai, Yasukazu Nakaye and Susumu Imashuku (2012). Palmtop EPMA, Scanning Electron Microscopy, Dr. Viacheslav Kazmiruk (Ed.), ISBN: 978-953-51-0092-8, InTech, Available from: http://www.intechopen.com/books/scanning-electron-microscopy/palmtop-epma

\section{INTECH}

open science | open minds

\author{
InTech Europe \\ University Campus STeP Ri \\ Slavka Krautzeka 83/A \\ 51000 Rijeka, Croatia \\ Phone: +385 (51) 770447 \\ Fax: +385 (51) 686166 \\ www.intechopen.com
}

\author{
InTech China \\ Unit 405, Office Block, Hotel Equatorial Shanghai \\ No.65, Yan An Road (West), Shanghai, 200040, China \\ 中国上海市延安西路65号上海国际贵都大饭店办公楼 405 单元 \\ Phone: +86-21-62489820 \\ Fax: +86-21-62489821
}


(C) 2012 The Author(s). Licensee IntechOpen. This is an open access article distributed under the terms of the Creative Commons Attribution 3.0 License, which permits unrestricted use, distribution, and reproduction in any medium, provided the original work is properly cited. 